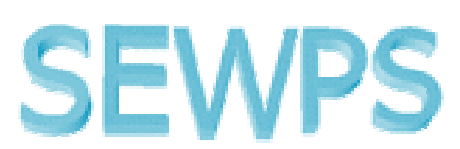

SPRU Electronic Working Paper Series

\author{
Paper No. 136
}

\title{
Making Design Rules: A Multi-Domain Perspective
}

\author{
Stefano Brusoni* and Andrea Prencipe**
}

( ${ }^{*}$ CESPRI, CRORA and Silvio Tronchetti Provera Foundation, ${ }^{* *}$ SPRU and University G. d'Annunzio)

\section{October 2005}

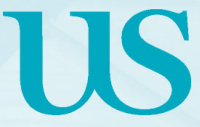

\section{University of Sussex \\ SPRU - Science \& Technology Policy Research}

The Freeman Centre, University of Sussex, Falmer, Brighton BN1 9QE, UK Tel: +44 (0) 1273678936

E-mail: a.prencipe@sussex.ac.uk http://www.sussex.ac.uk/spru/ 
Making Design Rules: A multi-domain perspective

\author{
Stefano Brusoni ${ }^{\star *}$ and Andrea Prencipe ${ }^{\text {vo }}$
}

'Bocconi University (CESPRI and CRORA) and Silvio Tronchetti Provera Foundation (Italy)

`Faculty of Economics, University G. d'Annunzio, Italy

"SPRU, University of Sussex, UK 


\section{Making Design Rules: A multi-domain perspective}

This study analyzes the processes whereby organizations develop radical innovations in response to environmental transformations. It explores the changes in organizational structures, practices and business strategies entailed by the implementation of such innovations. From the literature on modularity, we borrow the idea that the evolutionary dynamics of artifacts and organizations are linked by design rules, i.e. a set of principles that allocate functions to components, identify the operating principle of each component and determine the interfaces among modules. Through an in-depth case study of radical innovation in tire manufacturing, we study the joint dynamics of technical and organizational change during the transition from old to new design rules. We argue that technical change and organization adaptation are linked, but that such relationship is mediated and rendered open-ended by the evolution of the underlying bodies of knowledge. 


\section{Introduction}

This paper analyzes the processes through which an established organization adapts itself to a changing competitive landscape. It builds upon an inductive case study of radical change in the tire manufacturing industry. The case study develops the idea that the dynamics of organization design depends upon the evolution of the connections among their 'core elements' (Siggelkow, 2002: 126). The evolution of such connections appears fundamental to explain radical changes in business strategies (Siggelkow, 2001), organization structures (Romanelli and Tuhsman, 1994), institutional settings (Padgett, 2000), and organizational configurations (Miller, 1987; Grandori, 1997).

The organization design literature focuses on the nature of connections which renders organizations more or less likely to succeed in adapting to environmental changes. Some authors argue that tightly coupled organizations have major advantages when dealing with fundamental uncertainty, as tight coupling among elements makes them more sensitive and responsive to the environment (e.g. Weick, 1976). Others argue that tight coupling prevents organizations from adapting rapidly: since each change entails many interrelated changes, inertia is the most likely outcome (e.g. Levinthal, 1997). Such issues are core to recent research on modularity (Langlois and Robertson, 1992; Ulrich, 1995; Baldwin and Clark, 2000). Fundamental to this literature is the concept of design rules (Baldwin and Clark, 2000), i.e. the principles that allocate functions to components, identify the operating principle of each component, and determine the interfaces among modules. Design rules are routines that govern interfaces at the product and organizational domains. Within the boundaries set by design rules, modularity renders complexity manageable by making it possible to run parallel experiments that pursue alternative explorative paths at the level of modules (Baldwin and Clark, 2000).

In the literature, many authors argue that the adoption of modular design strategies at the product level would lead to modular organizations: products design organizations (Sanchez and Mahoney, 1996; Schilling, 2000; Sturgeon, 2002). The latter represents the null hypothesis of our study and identifies what candidate 'core elements' (Siggelkow, 2002) we have adopted in our empirical work: the product and the organization. By 
product, we mean the manufacturing plant (not the tire) as an instance of complex artifact made up of many interconnected elements. By organization, we mean the network of people and activities that interact to design and manufacture the tire. Our aim is to analyze the process through which an organization develops a radically new technology and to explore how such choice affects the design of the organization itself. We look empirically at the development process of new design rules, as the latter define the connections between technological and organizational changes. Unlike extant literature on modularity, we argue that such relationship is mediated and rendered open-ended by the evolution of the underlying bodies of knowledge

This paper aims to deliver two contributions. First, it analyzes how breakthrough innovations are introduced in complex organizational systems looking at the joint dynamics of artifacts, organization and - crucially knowledge. Second, it analyzes how organization design and organization emergence interact during phases of technological and organizational turmoil. The discussion is structured as follows. The next section illustrates the research method adopted. Section 3 presents the results of the inductive case study of breakthrough innovation in tire manufacturing. Section 4 deepens the discussion of the case study and relates them to recent developments in organization theory. Section 5 concludes.

\section{Research Method}

This paper reports the preliminary results of an ongoing study of the international tire industry. The overall aim of this study is to understand, in a micro-funded way, how mature businesses can be rejuvenated, what the challenges are, where the opportunities come from, what are the implications for firms' strategies and industry dynamics. Although the literature often depicts the tire industry as the archetypical example of mature business (Sull, Tedlow, and Rosenbloom, 1997; French, 1991), as from the early 1990s it has witnessed an explosion of R\&D initiatives which impinge upon all levels of the value chain. Everything appears to be in discussion: business models, product characteristics, technological competencies, and organizational structures. The focus of this paper is on one specific instance of radical technological change 
introduced by one of the world's leading firm in the sector. The aim of this section is to clarify why this instance was chosen, what we did, and how.

In the late 1990s, the trade literature as well as the general press gave wide visibility to ongoing developments of fully robotized and modular production process. The process, developed by Pirelli ${ }^{2}$, a leading player in the international tire industry, is called MIRS: Modular Integrated Robotized System. According to the trade press, MIRS ushered in the era of tire as customized system. A thorough review of the trade literature, preliminary patent analysis (Acha and Brusoni, 2005) and some pilot interviews sketched the picture of a mature sector suddenly pushed into action by a number of exogenous pressures and internal developments. Such changes seemed to be leading the major industry players to reconsider not only their products and process technologies, but also the business model which had dominated the industry since the late 1960s (i.e., the time of the radial revolution, the last major technological breakthrough in the sector).

We approached Pirelli to gain access to primary data about the robotized process they developed. The early contacts led to a first meeting with the managing board of the company to discuss aims and objectives of the project, and data access. Crucially, a company tutor was appointed with the task of introducing the researchers to the subjects of the analysis. This tutor was a senior engineer (Renato Caretta), member of the managing board, former senior $R \& D$ executive officer, and the person who actually led and conceived the project which developed the innovative process.

\section{Sampling}

The purpose of the study is analyzing the development process of new design rules. We therefore required a case that would represent an example of a major redesign of a technology, or product, and the organization underpinning that technology or that product. We chose to analyze the specific case of radical innovation in process technology because manufacturing seemed to us the real bottleneck of the entire sector. Traditional tire manufacturing had not changed substantially since the radial revolution of the late 1960s. Robotized,

\footnotetext{
${ }^{2}$ Throughout the paper, Pirelli is intended to mean Pirelli Tires (Pirelli Pneumatici). The company has explicitly agreed on waving their right to anonymity.
} 
modular production, however, seemed to have the potential to change the key heuristics on which practitioners had relied for over a century: mass production, standardized products, and exploitation of economies of scale. Robotized processes aim instead at scope, flexibility, and customization. Alternative units of analysis were available at the product level (e.g. tires embodying sensors, wheel systems integrating tires and breaking components) but none of them had reached commercialization when the study began. We then selected this instance of radical process breakthrough. Within the industry, we selected this specific company as a case study for two reasons. First, Pirelli was the first company to succeed in commercializing products manufactured with the new process. Second, the main alternative (i.e. Michelin) has an established reputation of secrecy which has, historically, prevented researchers to carry out in-depth analysis of their strategies and processes. Besides, there was of course an issue of convenience related to the possibility of performing interviews in the mother tongue of all the parties involved.

Within the company, the sampling strategy followed the principles of theoretical sampling. First, we identified, relying on the tutor and secondary sources, three individuals who played a key role in kicking-off the development project. Such individuals were instrumental in defining the major milestones of the development project (e.g. opening of the first pilot plant) which were accompanied by some form of organizational transformation (e.g. new people were hired into the team). The people who became part of the project at such junctures were then included in the sample of interviewees. Two key criteria were chosen to select the people to add in the sample. First, their contribution to the development process in terms of product design capabilities, software design capabilities, and quality control managers. Second, their involvement in the project until its completion. This sampling stopped when we reached what Glaser and Strauss (1967) called theoretical saturation. Each new interviewee indeed added information useful to enhance our understanding of the process, but did not add any new theoretical categories to the analysis, or new milestones to the timeline of the project, nor new critical problems.

\section{Interviews}

The paper builds upon different types of data, namely interview, patent, archival, product, and quality assurance databases. This section focuses on interview data. Other data sources are described below in this 
section. The fieldwork was divided in three stages performed in 2004. The interviews were carried out in Italian. A first round of interviews took place between January and March. This was followed between April and mid-June by the analysis of the interview data with follow up phone calls and email exchanges with the interviewees to corroborate and clarify specific points. During the third stage, a second round of interviews took place between late June and the end of September. Follow-up phone calls and email exchanges were used to clarify details. We interviewed twenty-seven different individuals, some of them repeatedly, for a total of about 75 interview-hours.

During the first part of the study, interviews were carried out using an unstructured schedule. A few of them were actually performed while the interviewer was being walked through the plant. The thrust of these interviews was to understand the process and its differences with the old one; understand the organization, how it had evolved and the key members in it; against which competitive background the development project had started; stimulate the interviewees to reveal lines of investigation; which data were available to validate the interview data. We focused on what Strauss (1987) called generative questions. The second round of interviews was more 'problem-oriented' (Flick, 2002: 125). They were designed to understand issues emerging out of the analysis of the interview notes from the first stage and from the analysis of the quantitative data (see below). All interviews were structured around three types of questions: conversational entry (e.g., what does that robot do? How long have you worked here?); generic and specific prompting to deepen and clarify specific issues already touched upon (e.g., summarizing in the interviewer words what had just been said by the interviewee); ad hoc questions (e.g., can you explain why your quality system identify so many/few problems in this specific area? Why is this criticality not even mentioned concerning the traditional process?). The balance between these types of questions changed considerably as the case study proceeded, shifting towards more specific questions as we went along.

All interviews were carried out by the same researcher, in Italian, who came to play three roles in succession. First, with respect to the tutor, and particularly during the first three months of fieldwork, the interviewer played the role of a sort of a biographer writing a narrative. The tutor provided a thorough, and largely uninterrupted, narrative reconstructing the evolution of the industry, the company (where he has spent his 
entire career) and the technology he contributed to develop. Such method of interview (i.e. few, broad questions, with minimum interruptions and further questions largely left to the end of the interview to summarize the main thrust of the narration) was used mainly with the tutor. He was the most senior person in the sample, he had played a key role in the development project, and he had campaigned for it before it was sanctioned by the CEO. The narration's focus was of course provided by the specific technology whose evolution we chose to study.

The other two roles that the researcher played emerged when the more structured and problem-oriented interviews were performed. The researcher was first accepted as a visitor (Agar, 1980) with some inner knowledge of things (but still an external member engaged in a learning process from the outside). Later, and largely during the analysis of the internal documents, the researcher approached the status of an initiate (Agar, 1980), due to the fact that some of the indicators developed during the study revealed things that the interviewees could not promptly categorize as 'right' or 'wrong'. The ensuing discussion involved the researcher too, who became a potentially useful counterpart. Adler and Adler (1987) might consider this as a situation of peripheral membership.

\section{Data analysis}

All interviews generated detailed field notes. The researcher took field notes during the interview. All interviews were scheduled in such a way to have at least half an hour in between (and possibly not more than two interviews per day). Such gap in between interviews was needed to organize the notes, identify quick come back questions and articulate the first impressions and interpretations stemming from the interview. A short documentation sheet was also prepared for each interviewee, listing their job title, task, background, start date of their involvement with the project. The interviews were not taped. This was an explicit request of the managing board. While the lack of precise transcripts exclude the possibility of carrying out textual analysis, the advantages are also remarkable. The interviewees, particularly the less senior ones, felt more confident and free in expressing their views. Moreover, some of the interviews were performed in the plant or other (noisy) laboratory environments. Most interviews were complemented by notes taken by the interviewees themselves during the meeting. Most of them used to draw diagrams to explain specific points 
about their work, clarify technical details of the process, explain tire properties, and describe the software infrastructure or the layout of the plant.

In terms of coding, a very simple form of thematic coding was used (building upon Stake, 1995 and Creswell, 2003). After each interview, a short description of the 'case' was written, reporting a short description of the interviewee, the context of the interview, and the main points raised with respect to the development project. Each case was meant to add a new facet to the emerging picture of the new process. Some cases stressed the technological part of the project; others the product-level implications, others the issues opened up by a fully robotized process with respect to a quality system which had been designed to deal with a more labor-intensive process; others again stressed the organizational and strategic implications of the project. The problem-oriented interviews carried out in the final stage of the fieldwork lent themselves particularly well to this type of analysis.

\section{Validity}

To establish the validity of our analysis, we relied on data triangulation. Following Denzin's (1989) typology of triangulation methods, we searched for data sources capable of giving us an overview of the same phenomena from different viewpoints. To do so, we relied on quantitative and qualitative data sources. As regards the latter, the researcher interviewed three of the top managers involved in taking the decision to go ahead with the project at critical junctures. These interviews were meant to confirm the centrality of the project to the firm strategy. The researcher interviewed the leader of the newest and most ambitious R\&D project ongoing at the time of our study, to have an external - yet informed - view of the extent to which the project we studied was actually considered a breakthrough for the firm at the time it was launched as an R\&D project. Eventually, the sample included also three leading engineers of the business units which still relied on the traditional manufacturing process (i.e. a senior manager of the division in charge of the entire car tire platform; one of the senior tire designers; one of the senior plant managers). All of them were interviewed at length to validate two central claims emerged from the fieldwork. First, the novelty of the new manufacturing process with respect to the old one. Second, and more importantly, the cascade effects that the development project was being told to have on other business units within the firm. To further 
validate the latter point, we also interviewed one senior manager in charge of transferring one key technical result achieved during the development phase of the project we studied, to the production process of truck tires.

Quantitative data include patent, archival, product, and quality assurance databases. They were used to validate a number of claims about the reasons that brought the company to invest in this new process. Archival data and trade literature were accessed to develop a thorough understanding of how the company articulated its own strategies in the mid 1990s, i.e. just before the development project was launched; and how (if) that changed in the following years. Internal documents stored in the archive provided us with invaluable information about the size of the project, in terms of people and resources, its internal visibility, the commitment of the top management and the like. Patent data at industry level were used to analyze the innovative strategies pursued by the leading firms (Acha and Brusoni, 2005). We relied on European Patent Office data mainly to validate the list of the key people we sampled. The idea was to use this publicly available source of data to double check on the accuracy of our sampling method. Besides, the analysis of the time series of patents allowed us to validate also claims about the existence of relevant process capabilities in-house before the beginning of the project. The existence of such process-level capabilities emerged as a key element in our theoretical interpretation of the phenomenon. Product data internal to the company were also analyzed to confirm the increasing segmentation of the market place.

We also used quantitative data to validate specific claims about key problem areas that emerged during the project as well as to substantiate claims about the differences between the new and traditional processes. With respect to the latter issues, the Failure Mode and Effect Analysis (FMEA) database was a fundamental source of data. This database reports very detailed information about the production process. It is produced as part of the procedures to obtain an ISO-9000 certification. The database contains information about the identified criticalities of the production process. For each problem, causes and solutions are listed. For each problem, indicators are developed to highlight the frequency of occurrence, the seriousness of the problem, and its difficulty. We accessed these data for two generations of the new process, and for the 'best' (i.e. the most efficient according to the firm own definition of plant efficiency) traditional process. We used these 
data to validate claims about the key advantages of the new process over the old one, as well as to validate claims about its conceptual diversity from the old one. This database was also very useful to inform the second round of interviews. For example, the project leader (i.e. our company tutor) was met repeatedly in order to discuss key issues stemming from the analysis of the FMEA spreadsheets. The latter seemed to identify issues and criticality areas of the new process that were not addressed during the first round of interviews (e.g. the evolution of the vulcanizer). This iterative process was fundamental to identify which problems and issues were construed by the researchers, and which problems and issues instead represented actual engineering challenges on which the group was still working. This phase was fundamental as it allowed us to achieve some degree of participation with the people working in the unit. For example, some of the aggregate indicators developed on the basis of the FMEA spreadsheet did not match the internal perception of the process as perceived by the interviewees during the first round of interviews. At this stage, we were granted use of a desk within the central office of the company, and one of us spent there about two and a half day per week over a period of nearly ten weeks.

\section{The making of a breakthrough in tire manufacturing}

This section illustrates the two main empirical building blocks of our story. First, we look at the reasons why Pirelli's top management decided in the mid-1990s to push forward the development of such breakthrough. Second, we analyze the organizational implications of MIRS. We highlight the development process of a new know-how to design and produce tires, to illustrate how the unfolding of MIRS included elements of design and emergence at both the technological and organizational level.

\section{The beginning of MIRS: innovation in the conventional process}

The trend towards automation and flexibility started as early as the 1980s. Pressures to reduce the average batch and increase the range of measures (i.e. the tire width) begun to grow, as carmakers struggled to improve safety and performance of their products. Most of the innovative efforts were focused on improving one critical step in the production process: building (or assembling). This is the stage when all raw materials and components need to be assembled to form the crude tire. Focusing innovation on the building phase allowed increasing process flexibility, reducing the average production batch and broadening significantly 
the range of tire widths that could be produced. Of course, more flexible building machines came at the price of losing economies of scale during the preparation of the raw materials and components. In addition, inventory costs rose rapidly because intermediate buffers had to increase to accommodate the smaller average batches processed during the building phase. In the 1990s, it became clear that some sort of threshold would be reached soon. While innovative efforts were reaching a ceiling, the number of market segments begun to rapidly increase. According to Pirelli own estimates, as from the mid 1990s the number of segments has nearly doubled. In parallel, established segments were also beginning to incorporate some of the sophisticated technical solutions originally developed for the high end of the market (e.g., sport cars, sport utility vehicles, etc.). Such developments in the market place were reported as one of the key drivers that pushed the company to develop the new process.

Within Pirelli, incremental improvements in the traditional process achieved two results. First, as intended, the company increased the flexibility of its manufacturing operations. A number of Pirelli employees, among whom our tutor, were heavily involved in this process of improvement of the traditional process. In particular, Renato Caretta emerged over the years as one of the key holders of broad and deep process capabilities. Second, such efforts generated a trickle of patents, which accumulated between the early 1970s and the mid 1990s. Such patents (less than ten until 1994) focused on the idea of building the tire on a solid drum. Such an idea was not new, as it dates back at least to the 1920s. Its key advantage consists in the elimination of a series of operations necessary to put into shape the flat support on which tire components are extruded. This operation is a major source of product imperfections. The bottlenecks to the development of the solid drum technology were related to how to move the drums and how to extrude composite material of the adequate quality with the necessary uniformity. Developments in robotics and software engineering (external to Pirelli) enabled the company to solve these problems.

\section{The making of MIRS: external and internal changes}

In the mid-1990s, Pirelli was in a particularly difficult position for two reasons. First, the company was traditionally specialized in the medium and high end of the market, i.e. precisely those segments in which carmakers required more performing and customized tires. Company’s internal data and interviews confirm 
that as early as 1995 the trend toward product segmentation (by tire type and size) accelerated abruptly. At the same time, incremental improvements in tire assembling appeared to have reached their technological and logistical ceiling. Second, Pirelli was going through a period of serious internal turmoil, triggered by the 1992 failed bid to acquire one of its main competitors (i.e. Continental). The latter was in many ways the last effort to turn Pirelli into a mass producer of commodity tires. The subsequent shift in the internal balance of power led to a change in top management. Such a change was quite a shock for the entire group, because until then the Pirelli family had held a firm grip on the company. The changes in top management entailed also a change in the ownership structure of company, which in turn led to a major strategic refocus.

The first priority was to solve the serious financial and strategic issues inherited from the past. To cut short a rather long and difficult story, the group was reorganized around a few core areas, exiting or drastically downsizing unprofitable businesses, and investing heavily to improve efficiency and innovativeness in those areas identified as core business. In the 1990s some product divisions (e.g. fiber optics and real estate) other than tires begun to acquire prominence and great visibility and begun to cast a shadow on the traditional central role played by the tire division. Industry reports and interviews confirm that at that point in time the tire division was losing its central position in the industry, if not by market share, at least as lead innovator. Interview data confirm that, besides market shares or profitability, concerns were being raised by some of Pirelli's key customers in the automobile market. Such concerns were focused on Pirelli's weakening role of innovator and supplier of top-of-the-range tires. Besides, archival data confirm that market shares by segment were at best static. Secondary sources, trade press, and interviews all confirm that Pirelli's key customers in the automobile industry expressed concerns about Pirelli's role in the industry: too small to be a big player in the commodity tire market, too big to be a niche player, and also seemingly losing that innovative edge which had given the brand its attractiveness and visibility over the years. Moreover, about in 1995 news begun to spread about a new robotized production process which Michelin was developing. Such process was supposed to give Michelin an advantage in the production of small batches of large tires, i.e. it appeared that Michelin (the market leader) was targeting exactly those segments which were Pirelli's traditional strongholds. 
Such combination of external and internal pressures culminated in the decision to invest in the development of MIRS. Such decision had a twofold target. First, the MIRS project was meant as a response to the increasing pressures of the automobile industry. Second, it was a signal launched by the top management (the CEO himself) to both competitors (Michelin in particular) and employees. From the beginning, MIRS was presented as the flagship project of the company. It was clearly part of the strategy of the new CEO (and owner) of Pirelli to revitalize the entire group. MIRS was meant to send a clear signal to the entire tire division. It was meant not only to change how tires were produced, but also how the whole of Pirelli worked. The message sent by the top management was that Pirelli had to start again thinking and acting innovatively. Internal documents are quite explicit in this respect: they emphasize enormously the efforts devoted to revitalizing the group and enable it to compete on international markets as leader in the high end of the market. Innovation was central to such strategy, and to its rhetoric. Beside MIRS, the company launched a major program of internal re-organization: new facilities were built, new marketing campaigns were launched, new distribution channels were searched.

These changes were pushed by the CEO himself. Indeed, MIRS was launched after distinctively brief internal consultations (very few documents were found in the archive). Was there internal opposition to the project? Interview data have highlighted that not everyone agreed on investing resources - and reputation on what was perceived as a very risky project. In addition, Michelin had already started investing in a project to robotize manufacturing: Pirelli was starting late in the race. The strong commitment of the CEO (and owner!) and the central corporate role assumed by Renato Caretta and by another individual who had previously collaborated with him (they appear as co-inventors in a number of patents) minimized organizational resistance to the project. In our view, rather than active resistance to change, the evidence points to a sort of passive resistance to it: inertia due to the problems of the recent past, more than strong strategic or operational disagreements.

The project started in September 1997. A group of four people led by the senior engineer (Renato Caretta) who held all the key - yet unexploited - patents, was given the responsibility to develop a new process. The group was freed from the daily need of efficient operations or short-term developments. The company 
CEO's words were reported to be: 'Do whatever you want, but come back with something!' The mandate was broad. The independence from functional responsibilities was complete. Caretta was the leader of the group, and he responded directly to the CEO. It was the first time that a group of people, with a budget, could get organized and focused on the problem of how to put in practice the intuition that tires can be built on a rigid drum. As stressed by Caretta himself, internally the group was flat, but for his own leading role. People, handpicked by the project leader on the basis of their technical capabilities, were removed from their departments and physically co-located in a new building. Open discussion and disagreement, followed by accurate testing, were encouraged. Many anecdotes tell a story of tight interaction, strong opinions, rewards for solutions found, and very direct remarks for mistakes.

At this early stage, the project objective was meant to revolutionize all phases of tire manufacturing, from rubber production to vulcanization and distribution. Quite rapidly, though, it became clear to the project leader and the members of the core team that it was necessary to adopt a narrower focus. In particular, the idea of introducing a new continuous process to produce the raw materials was soon set aside as it entailed problems too complicated and too far away from the core competences of the team (i.e. equipment and machinery). Also, the original idea of building plants that could be located next to the main clients' production sites faded away quite rapidly. A number of technical and strategic problems (namely, the unwillingness of carmakers to commit to one producer only) urged the team to focus on the effort to deliver a radical breakthrough in tire assembling and vulcanization.

\section{The making of MIRS know-how: from technological to organizational change}

After this early refocusing phase, the group moved swiftly through development and construction of the first robotized line, which opened in Milan in July 2000. Subsequently, robotized plants were opened in Germany (September 2001), UK (January 2002) and US (September 2002). Figure 1 summarizes the time line of the project, from its inception to the opening of the first full scale production facility. Despite the linearity implied by the figure, the process presented a number of challenges.

Figure 1 about here 
Since September 1997, after the early decision to abandon the search for changes in compound preparation, the project team considered MIRS as a major effort to revolutionize tire manufacturing and replace the traditional process. At this stage, problems focused on the types of machines needed and the logistics of the plant. The first question to answer was: 'Can rubber and other rubberized materials be extruded onto a rigid drum that is moved from extruder to extruder?' Despite holding patents which revolved around this idea, nobody in Pirelli had yet tried to implement it. Soon enough, it became clear that most problems related to the hardware could be solved through adaptations of 'off the shelf' equipment. The lay out of the plant also required to be reconfigured to accommodate the proper sequence of movements of the robots. Soon, other issues emerged to challenge the group.

First, the company had very little in-house capabilities in software engineering, because they were required to a limited extent by the traditional process. The efficiency of robotized processes, however, crucially depends on the software controlling the plant, which establishes the sequence of actions undertaken by the robots. After an early attempt to establish a joint research project with a local university, Caretta decided that such software had to be developed in-house: it was cheaper and faster. Thus, software engineers were hired into the MIRS unit from outside Pirelli, and trained about the specific problems of tire design and manufacturing. As early as mid-1998 (during the process development phase in figure 1), the organization began to adapt to the emerging needs imposed by the technology. It is worth noting that the MIRS group could adapt quickly because it was completely decoupled - even sheltered - from the rest of the organization.

As the software that governs the robots was developed, other issues emerged. Such issues concerned the process of tire design (not production), and how it was carried out. Traditionally, engineers had relied on distinctively tacit and specialized heuristics to design tires. For example, many of these tacit skills were held by those plant operators who had to manually operate the machines to implement the changes suggested by the designers. Computer-based design gave engineers the possibility and necessity to articulate such guesses in explicit cause-effect relationships. And they had to do it upfront, because they had to set the robots 
process parameters. The necessity to articulate such heuristics into procedures and parameters to be fed into the software emerged as a fundamental step in the development process, and its key bottleneck. It was at this point that it became clear that product engineers had to be involved in the project. It was them - not process engineers alone - who knew what characteristics of the tire lead to what performance. At this point the content of the project had changed again. It was not about the manufacturing process only. It was also about the tire design process.

The examples of two key components of the tire are worth reporting to underline what was going on: nylon $0^{\circ}$ and beads. The impact of a certain variation in the tension and angle of application of the 'nylon $0^{\circ}$ ' (a component used to hold together tire components) on tire performance was, at best, anybody's guess. In the traditional process, there is just one way to apply nylon: at one angle with one given tension. Changes in either require stopping the plant and manually adjusting the setting of the machine. In the new process, both angle and tension can be varied as the tire is built. The deposition of the nylon can be optimized with respect to the specific part of the tire which is being built (e.g. closer or farther from the sidewall) and the type of tire. Tire designers had no choice (or control) about this stage in the traditional process. The robotized process enabled them to gain degrees of freedom when choosing angle and tension. A parameter set by the machinery had therefore become a product design variable. In order to use it, however, designers were required to develop and articulate their knowledge about the consequences of changes in the angle of application and its tension.

Another example is beads. Beads application was one of the main sources of imperfections in traditional manufacturing. The bead is a key component as it connects the tire to the rim (a major source of stress for the tire, as well the key interdependency between the tire and the vehicle). Beads extrusion represents a critical step in both the traditional and robotized process. The bead is, basically, a metallic cord covered with rubber. In the traditional process, the bead is embodied into the tire by 'bending' the fringe of the tire itself onto it. This is a major source of irregularities in the tire. In the robotized process, beads are extruded directly onto the drum and then covered by the subsequent layer of rubberized material. No bending or stretching is required at all. With the traditional process, designers had few degrees of freedom. It all boiled down to the 
equipment available and the skills of the plant operator. With the robotized process, beads can be applied layer by layer, materials can be varied (within the same application cycle), extra layers can be added, etc. The tire designer acquires control and responsibility over what used to be a straightforward process issue, but at the same time he or she had to acquire the skills necessary to manage this new design variable.

The process of articulating such new engineering expertise led to a number of technological and - largely initially unintended - organizational consequences. The key problem was that MIRS was conceived as a process development project, reflecting the expertise of its first members. Product issues were given attention only much later. Engineers with product expertise became part of the project during late 1999 and early 2000. The new process at that point was already fully validated. The pilot plant had already been built (and a second was well under way), but there was no specific product to develop: it was a solution in search of a problem. At this point in time, the group, which had grown substantially, begun to fill the pressure to deliver. In the second half of the 1990s, the traditional business units had also begun to respond to the strategy promoted by the top management. As an effect, efficiency and productivity began to grow: new solutions were proposed and bottlenecks were removed to improve flexibility. At the same time, within MIRS, process validation had not been followed by a rapid increase in tire homologation by carmakers. As MIRS was not anymore an R\&D project, it had to show that it could be used not only to win awards granted from universities and learned societies (as it has done systematically), but also to produce commercially viable products. The delay in doing so generated quite a lot of internal discussion. This delay was due to two reasons.

First, it took time (longer than expected) to develop the product know-how necessary to use MIRS at its full potential. The examples we have given above (software engineering, beads, nylon $0^{\circ}$ ) are just a few instances of the problems encountered. Besides, each of these problems had to be solved for every and each new type of tire developed on MIRS. This was a lengthy process, which is still going on. Second, the economics of the process are such that, while technologically feasible to produce any kind of tire, it is the high end of the market that makes MIRS tires viable. However, the high end of the market is constituted of a series of rather small segments (e.g. tires for sport cars like Lamborghini). Fortunately, just about at the right time, two new 
and highly profitable market segments boomed: run-flat tires (soon to be linked with the launch of the extremely popular new Mini) and tires for Sport Utility Vehicles (SUVs). The latter is fastest growing market segment in Europe. The rigid sidewall of the former, and the large section width of the latter represented major challenges for the traditional process, but not for the robotized one. The emergence of runflats and SUVs gave MIRS some breathing space. While production for these two niches grew rapidly (from 2001 onward), engineers continued in their efforts to improve their new know-how.

The development of the product know-how led to a number of changes in the organization of design activities. In the traditional process, the interaction between designers and plant operators was managed through human and administrative interfaces. Tire design was a fragmented activity comprising sequential sub-steps performed by specialized designers whose interactions consisted largely of exchanging paperwork. Moreover, tire designers were organizationally and physically disconnected from the plant operators controlling the manufacturing process. The left-hand side of Figure 2 describes the main phase of tire design and production, and their duration. The new process led to a profound change in how tire designers work (right-hand side of Figure 2) and their know-how. The new production process enabled designers to gain unparalleled control over the manufacturing process. Through dedicated software, engineers - while designing the tire - were also able to set the process parameters that activate the robotized production process. This enormously streamlined the interactions between the design center and the manufacturing facilities, but it also shifted away from plant workers skills and responsibilities. The manufacturing process can now be fine-tuned to the specific needs of the particular tire under development. Figure 2 also provides an idea of the extent to which the time needed to go through one design-production loop is reduced with the new process, and the number of people involved in design.

Figure 2 about here

Nowadays, MIRS and traditional production coexist as they focus on different product segments. Besides, on the basis of MIRS achievements, incremental process innovations are being introduced also in the traditional process (the trucks division is particularly responsive). While MIRS was originally thought of as an 
alternative to traditional production, its development process has clearly showed that the two processes have complementary advantages and disadvantages. To conclude, the key challenge that had to be won was the development of a new engineering know-how underpinning tire design and manufacturing. Within MIRS, the old specialized know-how had to be abandoned and a much more integrated understanding of the entire design and manufacturing process had to be cultivated. Software engineers played a fundamental role in pushing process and product people to talk to each other. They helped establish strong personal connections through which new skills and capabilities were created combining existing ones. Within the project team, new connections were established, new skills developed, feedback loops begun to connect previously independent areas of action and expertise. Old organizational barriers broke down. The integration of process and product know-how meant the creation of a new kind of tire designer: an engineer responsible for, and competent about, the entire process of tire design, development, manufacturing and testing.

The activity of articulating and codifying engineering heuristics is still very much ongoing, product by product. Each time a new product is developed on MIRS, new data and expertise is acquired and articulated in parameters stored in the database management system. Process and product know-how are being collapsed into one new integrated body of knowledge which is mirrored in the new organization of design activities. This is the core result of our case study: the adoption of modular design rules at the plant level (the artifact in our analysis) did not lead to a modular organization of activities. Rather, new design rules led to the largely unintended development of an integrated body of engineering know-how. It is the latter that drove the evolution of the organization of design and manufacturing activities.

\section{Discussion: the making of design rules}

The literature on modularity builds upon the idea that products design organizations: the evolution of the artifact defines limits and constraints to organizational evolution. Is this proposition consistent with the results of our analysis? Undoubtedly, changes in the artifact (i.e. the production plant) have led to major changes in the organization of design and manufacturing activities through the development of a new body of engineering knowledge. Plant modularization bears indeed major implications for organization design. 
The empirical evidence discussed, however, does not show any linear relationship between the artifact domain and the organization domain.

Figures 3 and 4 visualize the different design rules embodied in traditional and robotized tire production. Design rules identify the architectural characteristics of each of the domains we have studied (i.e. the process, the organization and the engineering knowledge), their operating principles, and the connections among them. In traditional tire manufacturing, the plant is characterized by many, non standardized interdependencies and is therefore non-modular. Various raw materials (polymers, chemicals, fabrics, and steel reinforcements) are pre-processed and cut in discrete components, which are assembled to produce the tire. Plant interdependencies are managed through the creation of expensive buffers of inventories of raw materials, components, and intermediate products, which in fact play a key role in coordinating and smoothing the complicated production flow. In addition, changes in the process to accommodate changes in product characteristics require extensive human intervention to physically adapt machineries or move equipment around. Bringing all materials to the right place, in the right order, in the right sizes and compositions, and at the right time is a key logistics problem. Design rules in traditional tire manufacturing govern a non-modular production process operated by a modular organization, characterized by a tight and sequential division of labor (Figure 3). Product engineers, process engineers, plant operators rely on their own highly specialized skills and carry out their duties with infrequent and sparse interactions.

Figure 3 about here

In innovative tire manufacturing, the plant is modular. Production is characterized by a flow-line system that makes all components in their final shape so that conventional batch processes are eliminated. Each building process is focused around a rigid drum. All rubber parts are directly extruded onto the rigid drum in thin rubber strips. Similarly, textile plies are knitted in situ around the tire, while bead (i.e. the string of rubberized metal that holds the tire to the rim) wires, belts, and all reinforcement plies are deposited onto the drum as pre-extruded tapes of rubber-coated cords. Drums are carried to the machines by robots. When all raw materials are deposited on the drum, this latter is brought to the curing phase by a robot. Each module is 
a self-contained assembling and curing plant that operates on a smaller scale than a traditional plant. The process can be scaled up by adding additional modules. Innovative tire manufacturing embodies therefore different design rules from the traditional one. Design rules govern a modular production process operated by an integrated organization and integrated know-how (Figure 4).

Figure 4 about here

Our empirical evidence suggests that changes in the organization domain were not determined by changes in the artifact domain. Although it was the strategic decision to develop MIRS which triggered transformations in both the organization and know-how domains, MIRS key feature (i.e. modularity) does not define the characteristics of the organization and of the engineering know-how we have observed. The case evidence illustrates that what was not modular (the production process) became modular and what was modular in the traditional production system (know-how and organization) became highly integrated. The evolutionary dynamics of the three domains therefore followed dissimilar directions and reached different end states in terms of their internal topology. Our analysis of the changing internal topology of each domain adds another dimension to Siggelkow (2001) analysis of the changing patterns of relationship among organizations' core elements.

From an organization design perspective, our analysis highlights two results. First, the introduction of radical innovation requires changes that cut across different domains, i.e. the artifact, the organization, and crucially - the know-how. Feedback loops among domains were activated through a combination of external pressures (e.g. the emergence of new product segments due to the changes in the automotive industry), internal changes (e.g. changes of top management), and the emergence of a key individual (i.e. our tutor) who played a central role in all three domains. The interplay of these factors activated the process of development of new design rules and therefore the transition from the old to the new robotized manufacturing process. Such result is fully consistent with prior work on misfit and punctuated equilibria in organizational change (Romanelli and Tuhsman, 1994). We have observed such punctuation at a very deep level of analysis, i.e. the specific problems that had to be solved to introduce the breakthrough innovation. In 
so doing, we have observed that the transition from one configuration (Miller, 1987) to another was made possible by the creation of a set of non-modular connections among and within levels during the transition phase. This is what Padgett (2000) has labeled pliotropy, i.e. the presence of non-modular relations across domains that are necessary to generate non-incremental evolution.

Second, radical innovations are not introduced through acts of design and planning only. Design is one side of the coin. Emergence and adaptation are the other side. The original design decision by the CEO to create a small, autonomous group within Pirelli was vital to set things in motion. The original plan was far from being complete, however. For example, the criticality of the relationship between process and product knowhow was not foreseen when the project started and therefore the development of the new body of engineering knowledge became the key bottleneck of the project. The development of connections across the domains of artifact, know-how, and the planned organization unit of MIRS generated cascade effects across domains that led in turn to major results and changes to the original plan. Eventually the new integrated body of engineering knowledge became the major outcome of the project, an outcome which is also generating cascade effects on the organization of design and production in traditional business units.

Figure 5 captures the evolving nature of connections in the transition from the old steady state (Figure 3 ) to the new steady state (Figure 4). Each steady state is characterized by stable and predictable design rules among each domain. The analysis of the transition illustrates how design rules emerge, intensifying connections, establishing new ones, and breaking down existing ones. Stage 1 in Figure 5 depicts the situation in the 1970s and 1980s, when incremental innovations were introduced into the traditional manufacturing process to increase its flexibility, and patents were granted without following up on them. Although such emergent ideas and intuitions were not and could not easily feed back into the process, they laid the foundations for the introduction of the radical innovation. They in fact created a knowledge module on rigid drum-related ideas. This knowledge module is represented by a circle linked through a dotted arrow to the assembling phase of the plant-level network, with no connections to other knowledge modules, the artifact, and organization domains. This tiny, decoupled knowledge module reported in figure 5 (left) constitutes an element of continuity between the old and the new configurations. Even in the context of 
radical technological and organizational change, there were seeds on which the new top management could rely to introduce radical changes in strategy and attitude. The debate between advocates of 'creative destruction' and 'creative accumulation' (Pavitt, 1998) is therefore likely to continue.

The rigid-drum knowledge module grew (in terms of number of patents granted) until the mid 1990s, but it was only in 1997 that it developed connections with the organizational domain (solid arrow from top to middle domain in Stage 2 of Figure 5). The direct intervention of the CEO was essential: he set up the first embryo of the new process technology unit, put a in charge of it a senior engineer who was the holder of the vast majority of the relevant patents and who eventually acquired a central role in both the knowledge and organization domains (top and middle, respectively in Figure 5 - stage 2). In 1997, the unit was a decoupled organizational module within the firm (in fact no connections with the organizational domain are reported). The group started developing new knowledge (depicted by the connections characterizing the top domain) and prototypes of some manufacturing steps of the new process. This is represented by the dotted arrows that link the knowledge domain (top) with the artifact domain (bottom).

Figure 5 about here

As the group proceeded in validating the technology (through prototype building) new resources were introduced (e.g. software engineers, product engineers) thus strengthening the new connections in the knowledge domain and establishing previously missing connections between, for example, plant operation and tire design. The injection of new resources laid the foundations for the development of a new body of knowledge (i.e. the integrated understanding of product and process issues represented by the dotted circle in the knowledge domain in Stage 3 in Figure 5) to respond to the emergent knowledge and organizational requirements that were in fact imposed by the new manufacturing process and its software infrastructure. Also, new connections were being developed in the organizational domain. Over time the number of crossdomain connections grew (new connections were established) and became stronger (solid arrows in Figure $5)$. 
Eventually, a new configuration governed by new design rules was reached (Stage 4 in Figure 5, which simplifies Figure 4). This new configuration was obtained institutionalizing a series of connections among specialized skills previously highly modular (the new integrated product and process know-how). This know-how became embodied into a new organization of design work which integrated process and product engineers. In addition, the project team (whose internal organization was not changed) was transferred from the R\&D unit to the industrial operations division. Soon enough, a number of development projects in the traditional business units kicked off, inspired by the technological as well as organizational achievements of the development team. At the centre of such developments lies a new type of engineer, who embodies the integrated know-how (and bears the responsibilities which come with it).

\section{Conclusions}

Despite the enormous theoretical and practical relevance of the process through which organizations adapt to changing environmental characteristics, there are few micro-level empirical studies of this issue (e.g. Tushman and Anderson, 1986; Padgett, 2000; Tripsas and Gavetti, 2000; Garud and Munir, 2003; Siggelkow, 2001 and 2002). This paper was meant as a contribution to this stream of research. We have relied on the literature on modularity as it provides a number of distinctively strong statements and operationalizable concepts about the relationship between artifact and organization design. We have concluded that the artifact-organization relationship is mediated by knowledge dynamics. Our case study illustrates that the adoption of modular design rules in the artifact domain (i.e., the tire plant) is not accompanied by the emergence of a modular organization. Quite the opposite: modularity in the artifact domain was enabled by the integration that occurred in the organizational and knowledge domains.

While this specific result may well be explained by the specificities of the technology we analyzed, a number of general implications emerge from our study. First, the process of organization design is characterized by the continuous interaction of planned and emergent features. Our case study illustrates that the new organization emerged out of a development effort originally conceived as a process development project which outgrew the ambitions of its initiators. Second, fit among core components does not imply similarity. Organizations are complex systems that can be represented as interconnected networks (Padgett, 2000; 
Grandori, 2001). The topology of each network, however, needs not to look alike that of all the others. Modularly organized networks may co-exist with networks whose nodes are characterized by much more tightly coupled relationships. Third, the introduction of major innovations in complex systems requires that changes be introduced in a coordinated manner across these multi-domain networks. The activation and maintenance of feedback loops across the different domains is fundamental for the emergence of new design rules and, more generally, for the introduction of new business models. Tripsas and Gavetti (2000) show how failure derives from the lack of connections among an organization's core elements. Fourth, focal individuals who play a central role at all levels of the networks are fundamental to establish such feedback loops. Nevertheless, the outcome of such process of cross-domain rewirings (Padgett and Powell, 2003) cannot be fully predicted. The process of organization (re)design we have analyzed led Pirelli to introduce a range of changes that went well beyond their original expectations.

The point about focal individuals is consistent with traditional studies on innovation that found that successful product and process innovations require the presence of so-called champions. Allen (1977), Roberts (1987), and Rothwell (1990) concluded long ago that innovation is a people-based process. More recently, this line of enquiry has been enriched by a more precise theoretical understanding of what such champions actually do. For example, research on 'boundary spanning' role is quite pertinent to the results of our case study (Hargadon, 2003). Technology brokers recognize, store, blend, and transform technologies from the original context to new contexts of applications (Hargadon and Sutton, 1997). Besides the boundary-spanning function key individual play, the empirical evidence illustrated in this paper has also highlighted their integrating role. Our company tutor's career spanned the three domains and he created, through his career path, resilient (although not always strong) connections which eventually enabled him to introduce new design rules. We have emphasized the emergence of the new integrated body of expertise, while leaving brokering in the background. The integrating role of key individuals and specifically of the connections on which they found their activities, should be granted further empirical attention. For example, the catalytic role of focal actors in engineering intensive contexts has been observed in the analysis of the revamp of the development of the Rolls-Royce RB211 engine by Lazonick and Prencipe (2005). 
The case study has focused on the interaction between developments in the production process, the design organization, and design expertise. The evolution of the product has been only lightly touched upon. In a way, we considered its evolution as an antecedent to the introduction of the new process. More attention should nevertheless be devoted to it. After all, it is the product that is selected in the market place. And that is where, ultimately, the economic success of the robotized process will be assessed. Indeed, the vast majority of the modularity literature we have built upon looks precisely at the evolution of the product as the analytical starting point (e.g. Langlois and Robertson, 1992; Baldwin and Clark, 2000; Ulrich, 1995).

In addition, we have also not given adequate attention to the development process of the software infrastructure that provides the backbone to the new production process, and the organization that supports it. Research on this issue (e.g. D'Adderio, 2001) illustrates the role played by computer aided software tools in shaping how engineers work and interact. Deepening the analysis of the software infrastructure is fundamental to link our study to research about routines and how they emerge. One of the key problems tire designers in Pirelli had to solve was how to routinize their design activities on the basis of a different production technology and of a new IT infrastructure. Old heuristics and rules of thumb had to be abandoned and new ones had to be developed and shared first with the other participants to the project, than with other designers in the company. Understanding how it happened would help shed light on the process of emergence, and design, of organizational routines.

To conclude, our case study has illustrated the haphazard and roundabout nature of the development process of new design rules. Elements of design interact continuously with emergent properties. The dynamics of technology intersect that of organizations at strange angles. Dead-ends become extraordinary opportunities. At the very center of this very complex web of relations, we find people, with their careers, their choices, and their mistakes. This is our main conclusion. Whereas design rules do play a fundamental role in explaining the evolution of products, the rules of design remain largely people-embodied. In order to understand how design rules evolve, designers -and the skills and capabilities on which they rely- should be granted more attention. 
Figure 1. MIRS: development time line.

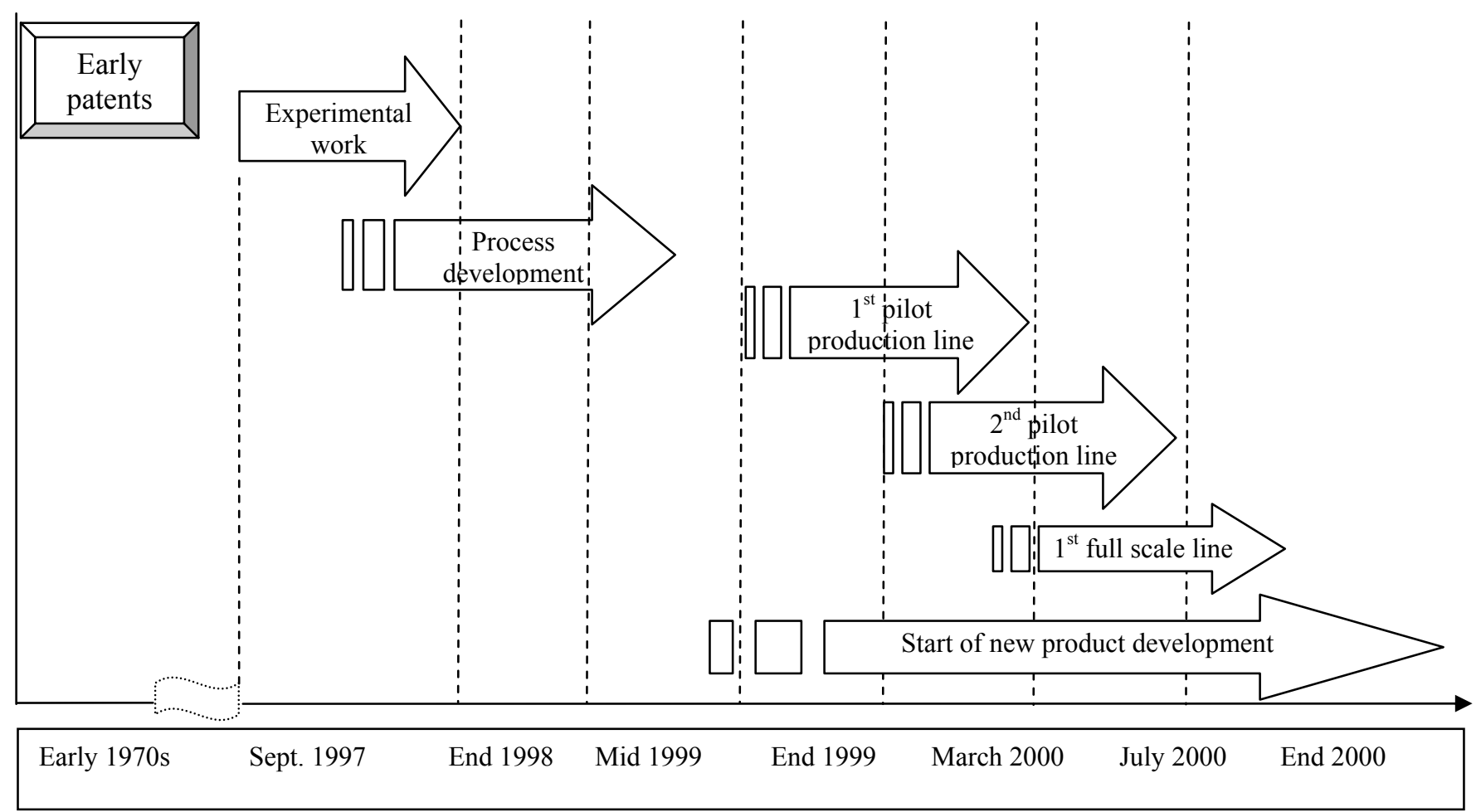

Source: authors' interviews and company internal document

Figure 2. Phases of design and production.

\begin{tabular}{|c|c|c|c|c|c|}
\hline \multicolumn{3}{|c|}{ TRADITIONAL PROCESS } & \multicolumn{3}{|c|}{ INNOVATIVE PROCESS } \\
\hline Activities & Responsible & Duration & Activities & Responsible & Duration \\
\hline Initial tire design & $\begin{array}{l}\text { Product } \\
\text { engineer }\end{array}$ & \multirow{4}{*}{ One day } & & \multirow{6}{*}{$\begin{array}{l}\text { Tire designer } \\
\text { (single point of } \\
\text { responsibility) } \\
\text { + specialists } \\
\text { (e.g. mould } \\
\text { designers) }\end{array}$} & \multirow{6}{*}{ One day } \\
\hline $\begin{array}{l}\text { Initial design of } \\
\text { components (e.g. } \\
\text { sidewall) }\end{array}$ & $\begin{array}{l}\text { Product } \\
\text { engineer }\end{array}$ & & Initial tire design & & \\
\hline Choice of materials & $\begin{array}{l}\text { Product } \\
\text { engineer }\end{array}$ & & Choice of materials & & \\
\hline $\begin{array}{l}\text { Tire design: sizing, } \\
\text { tread, etc. }\end{array}$ & $\begin{array}{l}\text { Product } \\
\text { engineer }\end{array}$ & & $\begin{array}{l}\text { Tire design: size, } \\
\text { tread, etc. }\end{array}$ & & \\
\hline $\begin{array}{l}\text { Definition of } \\
\text { building process }\end{array}$ & Process engineer & \multirow{2}{*}{ One week } & $\begin{array}{l}\text { Definition of } \\
\text { building process. }\end{array}$ & & \\
\hline $\begin{array}{l}\text { Final design of } \\
\text { components }\end{array}$ & Process engineer & & $\begin{array}{l}\text { Final design of } \\
\text { components }\end{array}$ & & \\
\hline Building, phase 1 & Plant operator & \multirow{2}{*}{$\begin{array}{l}\text { Two/three } \\
\text { days }\end{array}$} & & \multirow{3}{*}{ Plant operator } & \multirow{3}{*}{ Half a day } \\
\hline Building, phase 2 & Plant operator & & Building & & \\
\hline Vulcanization & $\begin{array}{l}\text { Vulcanizer } \\
\text { operator }\end{array}$ & One day & Vulcanization & & \\
\hline
\end{tabular}

Source: authors' interviews. 
Figure 3. The traditional tires design and manufacturing system.

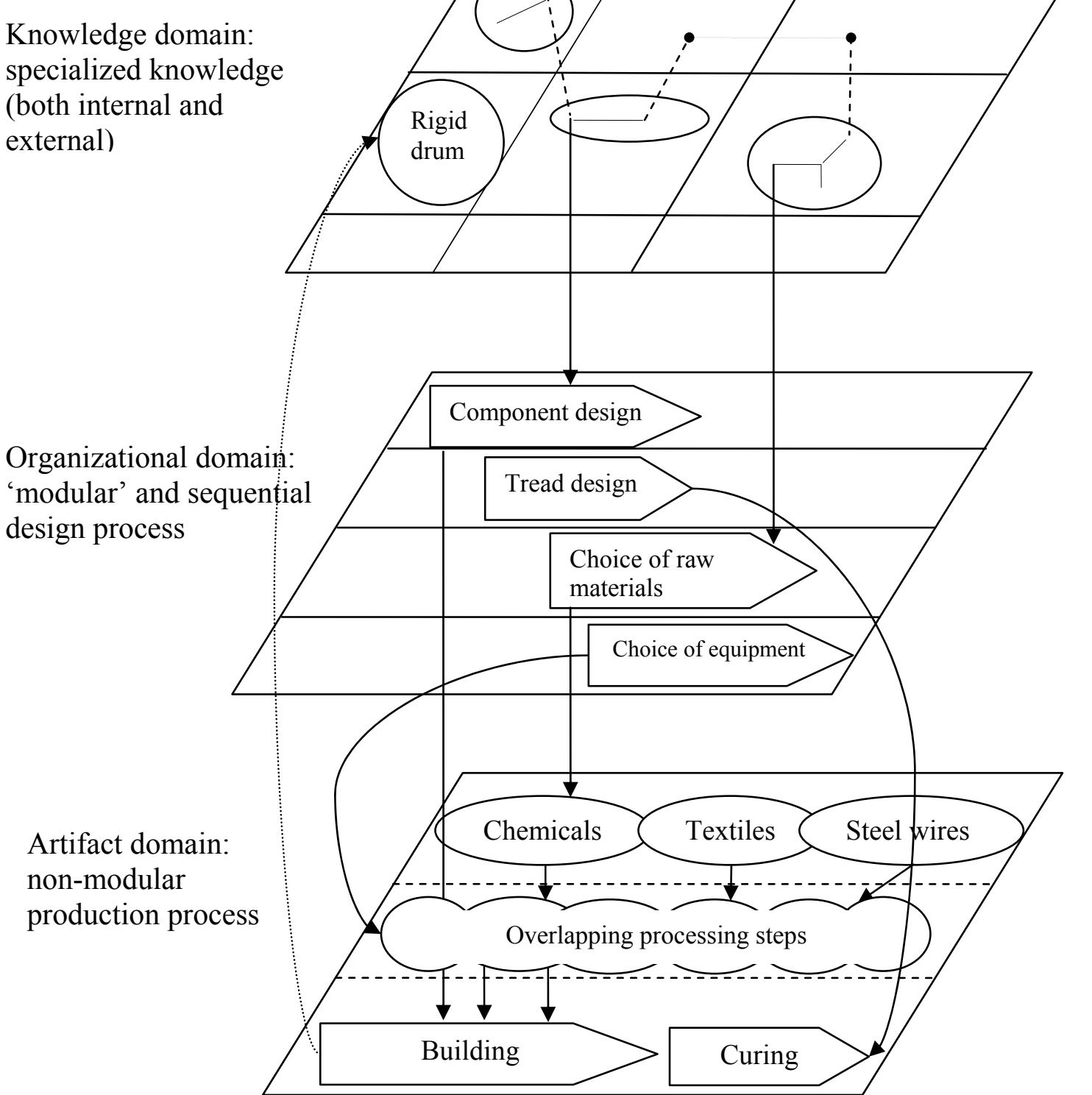

Note: Continuous arrows lines represent strong connections among levels or phases. Dotted arrows represent weaker connections. Horizontal continuous lines represent evidence of decoupling among phases or activities. Horizontal dotted lines represent evidence of tighter coupling among phases or activities.

Source: adapted from Padgett and Powell (2003) on the basis of authors' interviews. 
Figure 4. The new tires design and manufacturing system.

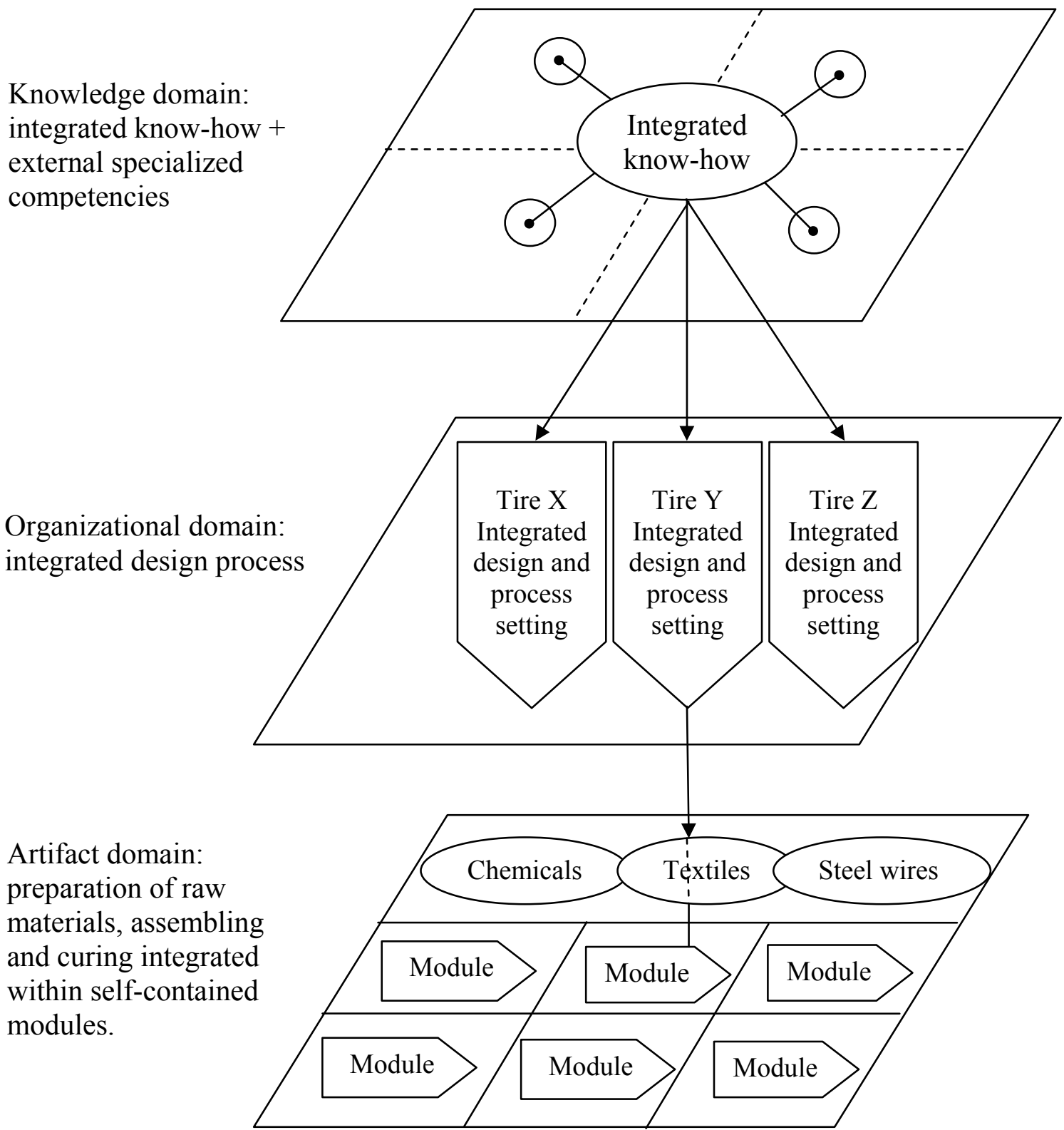

Note: Continuous arrows lines represent strong connections among levels or phases. Dotted arrows represent weaker connections. Horizontal continuous lines represent evidence of decoupling among phases or activities. Horizontal dotted lines represent evidence of tighter coupling among phases or activities.

Source: adapted from Padgett and Powell (2003) on the basis of authors' interviews. 
Figure 5. Evolutionary path of tire manufacturing process.

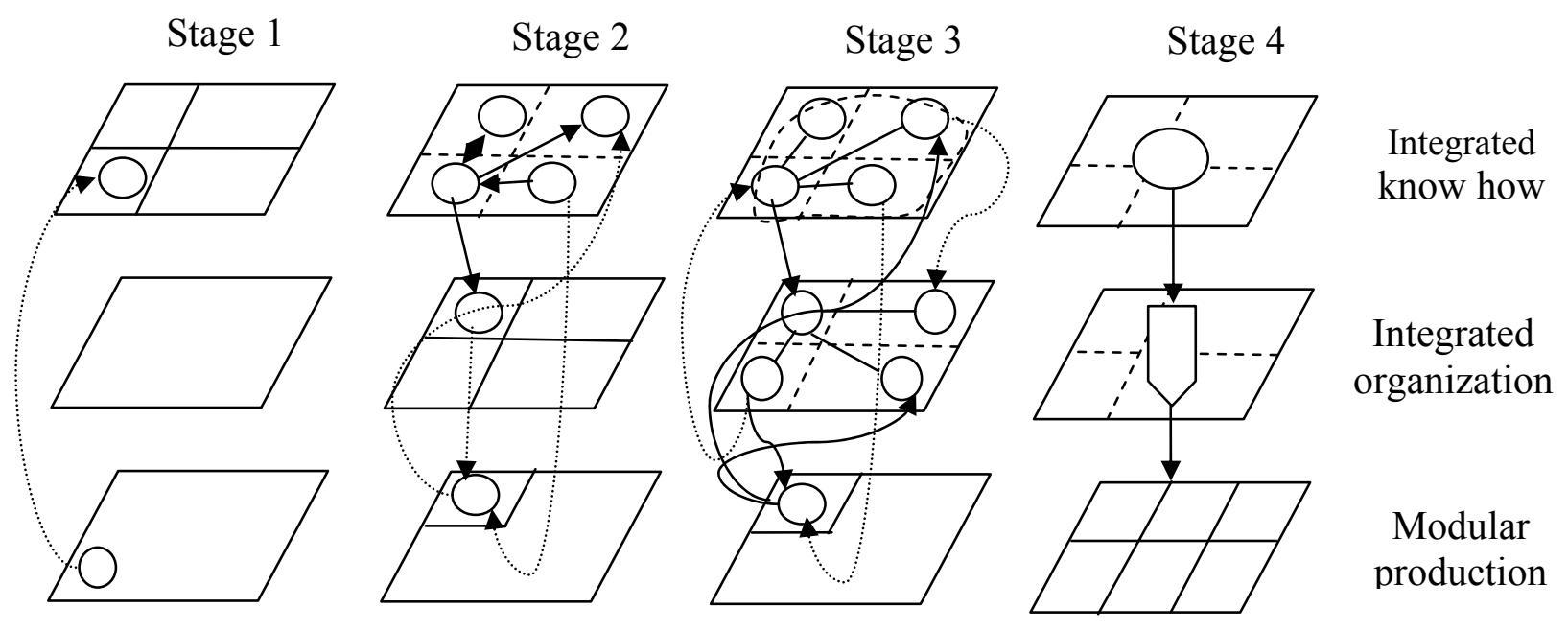

Note: Continuous arrows lines represent strong connections among levels or phases. Dotted arrows represent weaker connections. Horizontal continuous lines represent evidence of decoupling among phases or activities. Horizontal dotted lines represent evidence of tighter coupling among phases or activities. 


\section{References}

Acha V. and S. Brusoni. 2005. Complexity is in the eye of the beholder: Lessons from the tyre industry.

Finch J. and M. Orillard eds. Complexity and the Economy. Edward Elgar.

Adler P.A. and P. Adler. 1987. Membership roles in field research. Sage, Beverly Hills, CA.

Agar M. H. 1980. The professional stranger, Academic Press, New York.

Allen, Thomas J. 1977. Managing the Flow of Technology: Technology Transfer and Dissemination of Technological Information Within the R\&D Organization, MIT Press, Cambridge MA.

Anderson, P. 1999. Complexity Theory and Organization Science." Organization Science. $10216-232$.

Baldwin, C. Y., K. Clark. 2000. Design Rules (Vol. 1) The Power of Modularity. MIT Press, Cambridge MA.

Brusoni, S., A. Prencipe A., K. Pavitt . 2001. Knowledge specialization, organizational coupling, and the boundaries of the firm: why do firms know more than they make? Administrative Science Quarterly. 46 (4) 597-621.

Creswell, J.W. 2003. Research Design, Sage, Thousand Oaks.

D’Adderio, L. 2001. Crafting the virtual prototype: how firms integrate knowledge and capabilities across organisational boundaries. Research Policy. 30 1409-1424.

Denzin, N.K. 1989. The research act. Prentice Hall, Englewood Cliffs, NJ.

Drazin E. and A. H. Van de Ven. 1985. Alternative Forms of Fit in Contingency Theory. Administrative 
Science Quarterly. 30 (4) 514-539.

Flick, U. 2002. An introduction to qualitative research. Sage, London.

French, M. 1991. The U. S. Tyre Industry: A History. Twayne Publishers, Boston.

Garud, R. A. and K. Munir. 2003. Socio-technical dynamics Underlying Radical Innovation: The case of Polaroid's Sx-70 Camera. Presented at the conference 'What do we know about innovation? A conference in honour of Keith Pavitt'. 13-15 November. SPRU, University of Sussex at Brighton, UK.

Garud, R. A. Kumaraswamy. 1995. Technological and organizational designs for realizing economies of substitution. Strategic Management Journal. 16 93-110.

Glaser, B.G. and A.L. Strauss. 1967. The discovery of grounded theory: Strategies for qualitative research. Aldine, New York.

Grandori, A. 1997. Governance Structures, Coordination Mechanisms and Cognitive Models. Journal of Management and Governance, 1 29-47.

Grandori, A. 2001. Neither Hierarchy Nor Identity: Knowledge Governance Mechanisms and the Theory of the Firm. Journal of Management and Governance. 5 381-399.

Hargadon, A. 2003. How breakthroughs happen: the surprising truth about how companies innovate. Harvard Business School Press, Cambridge, MA.

Hargadon, A., R. Sutton. 1997. Technology brokering and innovation in a product development firm. Administrative Science Quarterly. 42 716-749. 
Langlois, R. N. 2003. The vanishing hand: the changing dynamics of industrial capitalism. Industrial and Corporate Change. 12 (2) 351-385.

Langlois, R. N., P. L. Robertson. 1992. Networks and innovation in a modular system: lessons from the microcomputer and stereo component industries. Research Policy. 21 297-313.

Lazonick. W., A. Prencipe. 2005. Dynamic Capabilities and Sustained Innovation: Strategic Control and Financial Commitment at Rolls-Royce plc. Industrial and Corporate Change. 14 (3) 501-542.

Levinthal, D. 1997. Adaptation on Rugged Landscapes. Management Science 43: 934-950.

Miller, D. 1987. The Genesis of Configuration. Academy of Management Review. 12 (4) 686-701.

Miller, D. and P. H. Friesen. 1980. Momentum and Revolution in Organizational Adaptation. Academy of Management Journal. 23 (4) 591-614.

Padgett, J. 2000. Organizational genesis, identity and control: the transformation of banking in Renaissance Florence. Casella A., J. Rauch eds. Markets and Networks. Russell Sage, New York.

Padgett, J., W. Powell. 2003. Economic transformation and trajectories: a dynamic multiple network approach. http://home.uchicago.edu/ jpadgett/papers/sfi/intro.chap.pdf, last accessed 13 July 2005, 17:14.

Pavitt, K. 1998. Technologies, products and organisation in the innovating firm: what Adam Smith tells us and Joseph Schumpeter doesn't. Industrial and Corporate Change. 7 433-452.

Roberts, E. 1987. Generating Technological Innovation, Oxford University Press, New York.

Rothwell, R. 1992. Successful industrial innovation: critical factors for the 1990s. $R \& D$ 
Management 22 (3) 221-239.

Romanelli, E. and M. L. Tuhsman. 1994. Organizational Transformation as Punctuated Equilibrium: An empirical test. Academy of Management Journal. 37 (5) 1141-1166.

Sanchez R., J. T. Mahoney. 1996. Modularity, flexibility, and knowledge management in product and organization design. Strategic Management Journal. 17 (Winter Special Issue) 63-76.

Schilling, M. A. 2000. Towards a general modular systems theory and its application to inter-firm product modularity. Academy of Management Review. 25 (3) 312-324.

Schilling, M. A., H. K. Steensma. 2002. Disentangling the theories of firm boundaries: a path model and empirical. Organization Science, 13 (4) 387-401.

Siggelkow, N. 2001. Change in the Presence of Fit: The rise, the fall, and the renaissance of Liz Claiborne. Academy of Management Journal, 44 (4) 838-857.

Siggelkow, N. 2002. Evolution toward Fit. Administrative Science Quarterly, 47 125-159.

Stake, R. E. 1995. The art of case study research, Sage, Thousands Oak. CA.

Strauss, A. L. 1987. Qualitative analysis for social scientist, Cambridge University Press, Cambridge.

Sturgeon, T. 2002. Modular production networks: a new model of industrial organization. Industrial and Corporate Change. 11 (3) 451-496.

Sull, D. N., Tedlow, and Rosenbloom D. N. 1996. Managerial commitments and technological change in the US tire industry, Industrial and Corporate Change, 6 (2) 461-501. 
Tripsas, M. and G. Gavetti. 2000. Capabilities, Cognition and Inertia: Evidence from Digital Imaging. Strategic Management Journal 21 (October-November) 1147-1161.

Tushman, M.L. and P. Anderson. 1986. Technological Discontinuities and Organizational Environments. Administrative Science Quarterly. 31 (3) 439-465.

Ulrich, K.T. 1995. The role of product architecture in the manufacturing firm. Research Policy. 24 419-440.

Weick, K. E. 1976. Educational Organizations as Loosely Coupled Systems. Administrative Science Quarterly. 21: 1-19. 